\title{
Unmanned Aircraft Systems for Remote Sensing of Vegetation Vigor
}

\author{
Michael G Wing* \\ Oregon State University, USA \\ Submission: July 17, 2019; Published: August 23, 2019 \\ "Corresponding author: Michael Wing, Oregon State University, Peavy Hall 280, Corvallis, OR 97331 USA
}

\section{Mini Review}

Advancements in unmanned aircraft systems (UAS) for remote sensing continue in terms of aircraft platforms and sensors [1]. These advancements include increased flexibility in platform flight capabilities and sensors that are becoming more light weight and powerful in terms of resolution. UAS flights can now be relatively easily controlled by mission planning software that can ensure that the entirety of an area is captured by imagery. When multiple images are necessary, as is typical with still photography, photogrammetric software can mosaic multiple images together to create a composite image.

Agricultural remote sensing has typically relied upon optical, multispectral, and hyperspectral sensors. Multispectral sensors have perhaps proved the most impactful among this group due to their relatively low cost and ability to generate the normalized differential vegetation index (NDVI). NDVI has long been used to infer vegetation health and stress through a band combination that involves red and near-infrared wavelengths [2]. Vegetation tends to absorb red wavelengths and reflect near-infrared (nearIR). The result of the NDVI band combination is a value that ranges from -1 to 1 , with higher values (nearer to 1 ) indicating a higher probability of vegetative health or greenness. NDVI values near 0 can indicate no greenness and possibly urban areas, and values near -1 likely indicating water.

Three UAS are presented here that include the ability to host multispectral remote sensors and represent a range of costs and capabilities. Each UAS platform can automate flight, including take-off and landing.

A popular and very light-weight multispectral camera is the Red Edge [3]. The latest version is the Red Edge $\mathrm{M}$ and weighs about $232 \mathrm{~g}$ with a compact form factor $(8.7 * 5.9 * 4.6 \mathrm{~cm})$. Five bandwidths are available and include blue $(475 \mathrm{~nm}, 20 \mathrm{~nm}$ bandwidth), green $(560 \mathrm{~nm}, 20 \mathrm{~nm}$ bandwidth), red $(668 \mathrm{~nm}$, $10 \mathrm{~nm}$ bandwidth), red edge $(717 \mathrm{~nm}, 10 \mathrm{~nm}$ bandwidth), near-IR (840nm, 40nm bandwidth). Costs for the Red Edge $M$ are about $\$ 5500$ USD. Ground scale distance (GSD) is approximately $8 \mathrm{~cm}$ per pixel when flown at $120 \mathrm{~m}$ above ground level (AGL). There are multiple aircraft platforms that can carry the Red Edge but one very affordable and reliable option is the Phantom 4 quadcopter series [4]. The latest version is the Phantom 4 Pro V2.0 which sells for about $\$ 1500$. The Phantom 4 Pro has a manufacturer stated flight endurance of 30 minutes but maximum flight times are likely closer to 15 minutes when bearing the Red Edge sensor. While not suited to larger areas due to its relatively limited flight endurance, the Phantom 4 and Red Edge combination (Figure 1) provides a compact and economical solution to those wishing to measure NDVI.

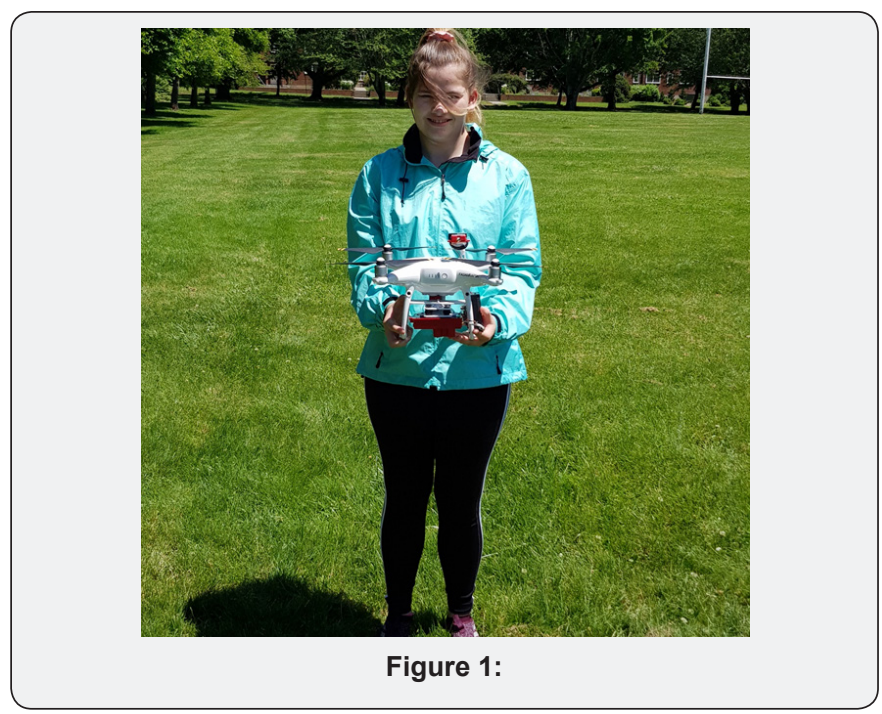

The Altum multispectral camera was announced in 2018 and is larger in weight and size than the Red Edge. The Altum weighs about $357 \mathrm{~g}$ and has dimensions of $8.2 * 6.7 * 6.5 \mathrm{~cm}$ [5]. Five spectral bands include blue ( $475 \mathrm{~nm}, 20 \mathrm{~nm}$ bandwidth), green (560nm, 20nm bandwidth), red (668nm, 10nm bandwidth), red edge $(717 \mathrm{~nm}, 10 \mathrm{~nm}$ bandwidth), and near-IR $(840 \mathrm{~nm}, 40 \mathrm{~nm}$ bandwidth). The resulting GSD is approximately $5.2 \mathrm{~cm}$ when flown at $120 \mathrm{~m}$. The Altum sensor costs approximately $\$ 9950$ USD. The Altum also includes a thermal sensor with a $160 * 120$ 
thermal resolution that results in an $81 \mathrm{~cm}$ GSD when flown at $120 \mathrm{~m}$.

An efficient and reliable aircraft platform for carrying the Altum is the Matrice 200 series [6]. The Matrice weighs approximately $4.7 \mathrm{~kg}$ when loaded with two batteries (Figure 2 ). The manufacturer stated maximum flight time is 38 minutes without a payload; the maximum takeoff weight is stated as $6.2 \mathrm{~kg}$ and results in a reported 24 -minute flight endurance. One could likely expect to achieve 25 minutes of total flight time from the Matrice when hosting the Altum. The Altum and Matrice combination is not as compact as the Red Edge and Phantom but does feature extended flight times.
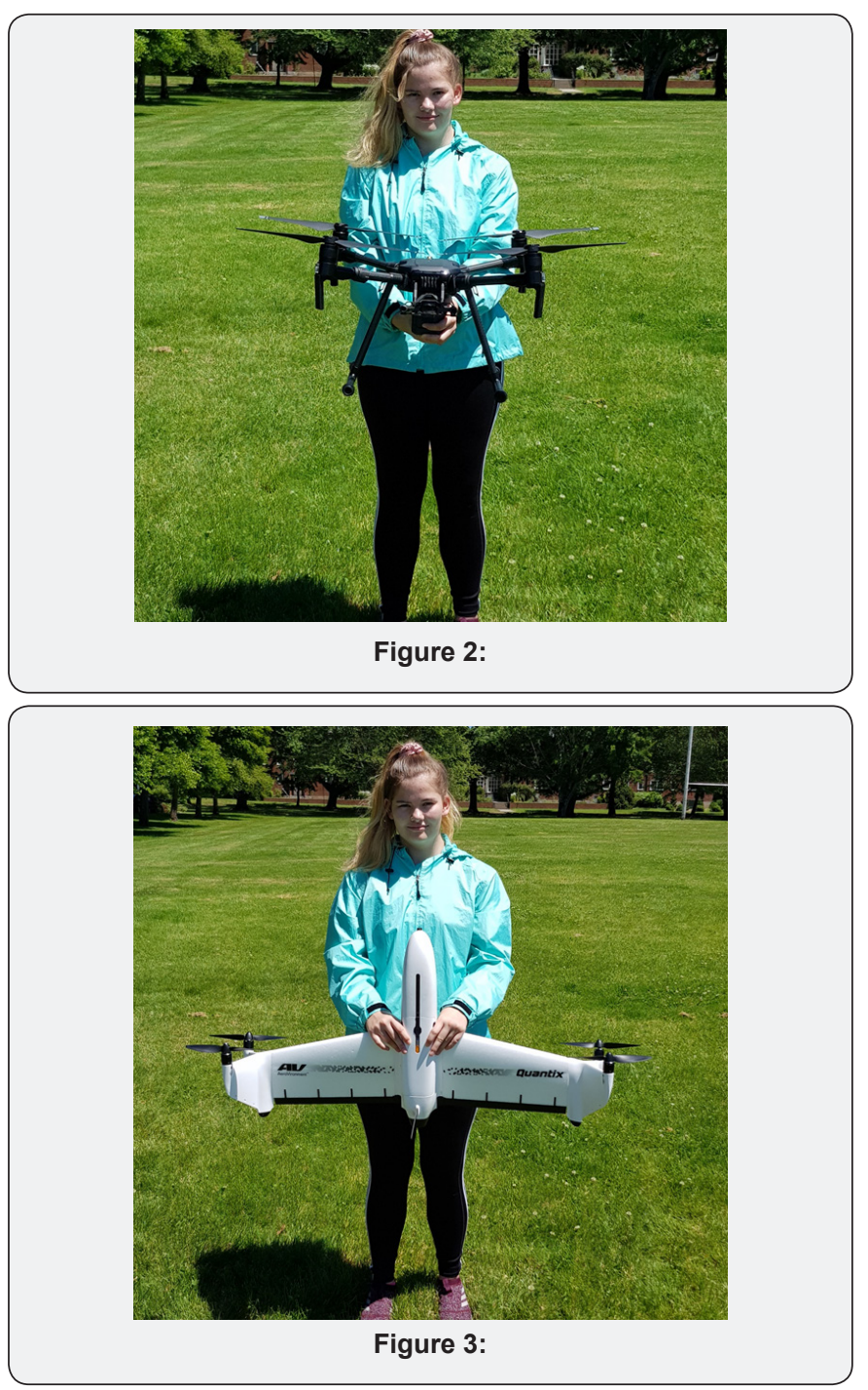

An option for imaging larger areas is the hybrid Quantix UAS [7]. The Quantix is a vertical take-off and lift (VTOL) platform. Four propellers support a vertical take-off and when airborne, the Quantix flies horizontally and gains an aerodynamic advantage through its fixed wings (Figure 3). The Quantix is large in comparison to the Phantom and Matrice with a wingspan of $1 \mathrm{~m}$. Vehicle weight is $2.3 \mathrm{~kg}$ when loaded with a battery. The reported maximum flight time is 45 minutes, with potentially up to 162 ha being imaged during a 45 -minute flight at $110 \mathrm{~m}$ AGL. The Quantix has dual 18MP cameras with one dedicated to optical and the other to multispectral. These cameras are integrated into the aircraft platform. The multispectral camera bands include green $(569.5 \mathrm{~nm}, 26 \mathrm{~nm}$ bandwidth), red $(626.5 \mathrm{~nm}$, $47 \mathrm{~nm}$ bandwidth), and near-IR ( $844 \mathrm{~nm}, 47 \mathrm{~nm}$ bandwidth). The resulting GSD of imagery from the multispectral camera is $5 \mathrm{~cm}$ when flow at $110 \mathrm{~m}$ AGL. The price for a basic Quantix package is $\$ 5500$ (USD) with an image processing subscription service being available. An advantage of the Quantix package is that a control tablet is included. One disadvantage is that direct manual control of a flight, in order to avoid obstacles or other unexpected features, does not appear to be possible. This may present some flight safety concerns.

Each of these three potential UAS platform and sensor combinations offers unique capabilities. For portability and affordability, the Phantom 4 and Red Edge camera combination is likely the best choice. The primary limiting factor of the Phantom 4 and Red Edge tandem would be difficulty in covering larger areas. While the Matrice and Altum combination has less portability, a larger area could be covered within a single flight and the resolution and capabilities (thermal) of the Altum camera are superior to that of the Red Edge camera. The Matrice and Altum are the most expensive of these three systems. The Quantix is a solid choice for those that need to cover larger land areas but it has some limitations in portability. The readily available image processing capabilities of the Quantix are an advantage for those that do not want to rectify and process their own data.

\section{References}

1. Wing MG, Burnett J, Johnson S, Akay AE, J Sessions (2014) A Low-cost unmanned aerial system for remote sensing of forested landscapes. International Journal of Remote Sensing Applications 4(3): 113-120.

2. Jones HG, Vaughan RA (2010) Remote sensing of vegetation: principles, techniques, and applications. Oxford university press 87(2): 165-166.

3. Mica Sense (2019a) Red Edge MX.

4. DJI (2019a) Phantom 4 Pro V2.0.

5. Mica Sense (2019b) Altum MX.

6. DJI (2019b) Matrice 200.

7. Aero Vironment (2019) Quantix. 
This work is licensed under Creative Commons Attribution 4.0 License

\section{Your next submission with Juniper Publishers} will reach you the below assets

- Quality Editorial service

- Swift Peer Review

- Reprints availability

- E-prints Service

- Manuscript Podcast for convenient understanding

- Global attainment for your research

- Manuscript accessibility in different formats

( Pdf, E-pub, Full Text, Audio)

- Unceasing customer service

Track the below URL for one-step submission https://juniperpublishers.com/online-submission.php 